\title{
A DANÇA E O MOVIMENTO TRADICIONALISTA GAÚCHO: entrevista com Paixão Côrtes
}

\author{
Christiane Garcia Macedo' \\ Silvana Vilodre Goellner²
}

\section{RESUMO}

O presente texto apresenta a entrevista com João Carlos D'Ávila Paixão Côrtes, folclorista e tradicionalista de destaque no Estado do Rio Grande do Sul, sobre a inserção da dança no Movimento Tradicionalista Gaúcho. Esse Movimento teve início entre o final da década de 1940 e início da década de 1950 e é relevante para o entendimento da identidade gaúcha. A dança é inserida apenas alguns anos mais tarde, por incentivo especialmente do 35 Centro de Tradições Gaúchas e do Grupo Tropeiros da Tradição. Na entrevista, Paixão Côrtes fala dessas primeiras iniciativas para recolher e divulgar as danças gaúchas, especialmente os conjuntos artísticos que se estruturaram na época. Essa entrevista está integrada ao projeto Garimpando Memórias (CEME / ESEFID / UFRGS).

Palavras-chave: Dança. Tradicionalismo. Rio Grande do Sul. Entrevista.

1 Doutoranda em Ciência do Movimento Humano. Universidade Federal do Rio Grande do Sul (UFRGS). Porto Alegre/ Rio Grande do Sul, Brasil. E-mail: chrisgmacedo@gmail.com

2 Doutora em Educação. Professora da Universidade Federal do Rio Grande do Sul (UFRGS). Porto Alegre/ Rio Grande do Sul, Brasil. E-mail: vilodre@gmail.com

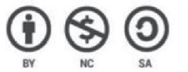

Este texto está publicado sob uma licença Creative Commons Atribuição NãoComercial-CompartilhaIgual - CC BY NC AS 
DANCE AND THE MOVIMENTO TRADICIONALISTA GAÚCHO: interview with Paixão Côrtes

\section{ABSTRACT}

This text presents the interview with João Carlos D'Ávila Paixão Côrtes, folklorist and traditionalist of prominence in the State of Rio Grande do Sul, on the insertion of the dance in the Movimento Tradicionalista Gaúcho. This movement began between the late 1940s and the early 1950s and is relevant to the understanding of the Gaúcho's identity. The dance is inserted only a few years later, especially because of the 35 Centro de Tradições Gaúchas and Grupo Tropeiros da Tradição. In the interview Paixão Côrtes speaks of these first initiatives to collect and publicize traditional dance of Rio Grande do Sul, especially the artistic ensembles that were structured at the time. This interview is integrated with the project Garimpando Memórias (CEME / ESEFID / UFRGS).

Keywords: Dance. Traditionalism. Rio Grande do Sul. Interview.

\section{LA DANZA Y EL MOVIMIENTO TRADICIONALISTA GAUCHO: entrevista con Paixão Côrtes}

\section{RESUMEN}

El presente texto muestra la entrevista con João Carlos D'Ávila Paixão Côrtes, folclorista y tradicionalista de destaque en el Estado de Rio Grande del Sur, sobre la inserción de la danza en el Movimiento Tradicionalista Gaucho. Ese Movimiento inició entre el final de la década de 1940 e inicio de la década de 1950 y es relevante para la comprensión de la identidad gaucha. La danza es inserida algunos años después, por incentivo especialmente del 35 Centro de Tradiciones Gauchas y del Grupo Troperos de la Tradición. En la entrevista, Paixão Côrtes habla de esas primeras iniciativas para recoger y divulgar las danzas gauchas, especialmente los conjuntos artísticos que se estructuraron en la época. Esa entrevista está integrada al proyecto Garimpando Memórias (CEME / ESEFID / UFRGS).

Palabras claves: Danza. Tradicionalismo. Rio Grande do Sul. Entrevista. 
João Carlos D'Ávila Paixão Côrtes é folclorista e tradicionalista do Rio Grande do Sul, além de compositor, radialista e escritor. Nascido em Santana do Livramento (RS), em 1927 foi um dos fundadores do Movimento Tradicionalista Gaúcho. Paixão Côrtes também escreveu várias obras sobre a cultura gaúcha como: Manual de danças gaúchas (1956), Festança na querência (1959), Terno de Reis (1960), Folclore musical do pampa (1960), Danças e andanças da tradição gaúcha (1975) e Aspectos da música e fonografia gaúcha (1985).

O Movimento Tradicionalista Gaúcho (MTG) teve início entre o final da década de 1940 e início da década de 1950, com o objetivo de preservar as tradições, visto que "o povo gaúcho, a massa popular citadina, parecia ignorar o seu próprio patrimônio cultural-tradicionalista" (CÔRTES, 1994, p. 37). Segundo Fagundes (2011), a influência norte-americana sobre a juventude brasileira no pós-guerra foi um dos elementos motivadores do surgimento do MTG, uma espécie de reação de alguns rapazes que rejeitaram essa influência e começaram a implementar ações em prol da preservação das tradições de seu povo. Paixão Côrtes foi um dos líderes do Departamento de Tradições Gaúchas, fundado no Grêmio Estudantil do Colégio Júlio de Castilhos (Julinho), em Porto Alegre, no ano de 1947. Esse Departamento organizou alguns eventos com o objetivo de rememorar fatos importantes da História do Rio Grande do Sul, tais como a Guerra da Cisplatina e a Guerra dos Farrapos.

As reuniões dos jovens do Julinho eram frequentes nesse período e várias pessoas se agregaram a este movimento, como Glauco Saraiva ${ }^{3}$ e Barbosa Lessa ${ }^{4}$ que, juntamente com Paixão Côrtes, fundaram, em 24 de abril de 1948, o 35 CTG $^{5}$ com o objetivo de resgatar e manter tradições gaúchas com destaque para poesias, contos e vestimentas. $\mathrm{Na}$ concepção de Barbosa Lessa (1954 apud CÔRTES; LESSA, 1975), o tradicionalismo deveria ser um movimento popular, que auxiliasse o Estado a reforçar o núcleo da cultura do povo.

As danças não integraram as primeiras iniciativas implementadas pelo MTG e, antes de sua criação, na década de 1940, são escassos os registros acerca de sua prática nos livros sobre folclore e nos jornais da época. Nesse sentido, o MTG contribui de forma indelével para recolher ${ }^{6}$ e divulgar a dança no contexto do tradicionalismo, processo realizado por meio de pesquisas e de contatos com pessoas idosas e do interior do Estado.

O 35 CTG possuía um departamento, conhecido como Invernada Artística, que era responsável por recolher e apresentar ao público músicas, contos e poemas relativos

3 Glaucus Saraiva da Fonseca, nascido em 1921, em São Jerônimo (RS), foi poeta, cantor, professor e apresentador de rádio, além de sócio fundador da Estância da Poesia Crioula e do 35 CTG. Escreveu a Carta de Princípios do Movimento Tradicionalista Gaúcho (MTG), documento que estabelece os princípios do tradicionalismo gaúcho.

4 Luiz Carlos Barbosa Lessa, nascido em 1929, na cidade de Piratini (RS), foi poeta, folclorista, escritor, músico, advogado e historiador.

5 Centro de Tradições Gaúchas.

6 Os folcloristas e tradicionalistas utilizam o verbo recolher para dizer que algo (verso, música, dança) foi registrado, na forma escrita, em desenho ou diagrama, a partir de observações na comunidade onde ocorriam, geralmente comunidades rurais ou pessoas mais velhas que se lembram dessas práticas tradicionais. 
à cultura gaúcha. A incorporação da dança se deu a partir de 1949, quando integrantes do 35 CTG e do Clube Farrapos da Brigada Militar participaram, em Montevidéu, de uma comemoração referente ao Dia da Tradição Uruguaia e lá visitaram três associações culturais que fizeram demonstrações de danças para receber os brasileiros: a Sociedad Criolla Dr. Elías Regules, a Sociedad Potros y Palmas e a Sociedad Artiguista.

Inspirados nesta experiência, Paixão Côrtes e Barbosa Lessa começaram a pesquisar sobre antigas danças do Rio Grande do Sul e as inseriram nas atividades desenvolvidas nos CTGs. Em função disso, no ano de 1949, ocorreu a inclusão das primeiras mulheres neste espaço dominado pelos homens cuja função estava relacionada à montagem de coreografias baseadas nas danças tradicionais. A primeira apresentação pública de dança gaúcha, pelo MTG, segundo as fontes consultadas para esta pesquisa, aconteceu no dia 22 de agosto de 1950, durante as comemorações da III Semana Nacional de Folclore, realizada em Porto Alegre, sob a organização da Comissão Gaúcha de Folclore (CÔRTES; LESSA, 1975). Uma vez aceita nas atividades do Movimento, a dança começou a integrar a rotina dos CTGs e as pesquisas desenvolvidas por Côrtes e Lessa resultaram na publicação, em 1955, do Manual das Danças Gaúchas, que se tornou um registro fundamental para a sua disseminação.

Em entrevista, Fagundes (2011) afirma que a introdução das danças gaúchas nos CTGs foi fundamental para a explosão do Movimento Tradicionalista, ampliando de modo significativo o reconhecimento dos CTGs e despertando o interesse para que muitas pessoas se aproximassem das agremiações tradicionalistas.

Na realidade vou dizer uma coisa que ninguém diz, e é verdade, foi a dança que fez a explosão do CTG no Estado, quando em 1950 o 35 foi convidado para visitar uma Associação em Montevidéu, tínhamos lá nossos rapazes e moças e viram as danças castelhanas [...]. Então o Barbosa Lessa e o Paixão Côrtes, que eram os líderes maiores da rapaziada, saíram para pesquisar nossa dança [...]. Absolutamente fundamental, as danças representaram a expansão do tradicionalismo e a criação de novos CTGs. (FAGUNDES, 2011, p. 6).

A divulgação da dança como um elemento importante da cultura gaúcha, amplamente divulgada pelo 35 CTG, acabou por inspirar a criação de outros espaços de cultivo das tradições gaúchas. "As pessoas que queriam fundar um CTG iam ao 35, e nós ajudávamos, levávamos uma invernada artística, cantores e declamadores. Fazíamos uma visita e a inauguração do CTG. Fizemos muitas vezes." (FAGUNDES, 2011, p. 5).

Um marco propulsor para a disseminação das danças no interior do MTG foi a fundação do Conjunto Folclórico Tropeiros da Tradição, uma iniciativa de João Carlos D'Ávila Paixão Côrtes. Seu protagonismo junto a este motivou a realização desta entrevista, que aconteceu por telefone no dia 26 de março de 2012, e integra o acervo do [trecho retirado para avaliação cega], cuja fundamentação teórico-metodológica ancora-se na

7 O órgão dedicado à divulgação dessa ciência no Rio Grande do Sul foi a Comissão Gaúcha de Folclore, ligada à Secretaria Estadual da Cultura, que foi uma das primeiras e mais ativas. Criada em 23 de abril de 1948, era vinculada à Comissão Nacional de Folclore. 
história oral. Muitos poderiam ser os temas priorizados para uma entrevista com Paixão Cortês, dada a sua enorme vivência junto ao tradicionalismo gaúcho. No entanto, para esta entrevista, optou-se por focar a inserção da dança nos CTGs em função dos poucos registros encontrados sobre essa temática.

\section{A ENTREVISTA}

[Entrevistadora X.X.] - Primeiramente eu gostaria de agradecer a oportunidade para a realização desta entrevista e gostaria de iniciar abordando o tema da inserção das danças nos CTGs ${ }^{8}$.

João Carlos D'Ávila Paixão Côrtes - Foi no 35 CTG que eu e o Barbosa Lessa fizemos as pesquisas. Pesquisávamos no interior, conforme está escrito em diversos livros, e iniciamos as danças. No Origem da Semana Farroupilha: primórdios do Movimento Tradicionalista ${ }^{9}$, um dos livros que eu escrevi, tem os principais responsáveis. Nele eu conto a história do nascimento da Semana Farroupilha ${ }^{10}$. Antes dele escrevemos, o Lessa e eu, os livros: Danças e Andanças ${ }^{11}$ e o Manual de Danças Gaúchas ${ }^{12}$. Pesquisávamos no interior e depois organizávamos como seria divulgado, em quais grupos, etc. Porque não existia grupo nenhum, nem no 35. Depois, eu fundei este grupo, que se chama Conjunto Folclórico Tropeiros da Tradição, em 29 de junho de 1953, dia de São Pedro. Este Conjunto começou a passar as danças às entidades, fazer espetáculos em eventos, teatros, rádios. Nesse tempo não tinha televisão, então levava este Conjunto aos palcos dos programas de rádio e este foi o início de todo este movimento. Mais adiante surgiram o 35 e as outras entidades, e parte do pessoal que dançava no 35 passou também a dar assistência aos grupos do interior. Eu dei muitos cursos e ensinei muitos grupos de dança. Esse sistema era pesquisado constantemente. Isso não foi de uma hora para outra, ele levou dez, doze anos. Eu estou escrevendo um livro agora com setecentas páginas no qual descrevo as pesquisas que eu fiz, muitas delas até agora desconhecidas.

X.X. - Como se deu essa divulgação?

J.C. - Do meu grupo, Tropeiros, saíram muitos rapazes para o interior. Eles davam assistência e explicavam como se dançava a chula, a chacareira, balaio, pezinho e tantas outras danças que até então eram completamente desconhecidas. Até porque também não

8 Centro de Tradições Gaúchas.

9 Côrtes (1994).

10 Celebra a Guerra dos Farrapos contra o Império que aconteceu entre os anos de 1835 a 1845 . Tem como marco o dia 20 de setembro e durante uma semana são realizados vários eventos que reforçam aspectos relacionados à cultura gaúcha.

11 Côrtes, Lessa (1975).

12 Côrtes, Lessa (1955). 
existiam Centros de Tradições, nem Escolas de Educação Física ou Centros Culturais da UFRGS $^{13}$, que eram as instituições que tinham conhecimento desses temas coreográficos. E por desconhecimento do professorado, do alunado e das instituições educacionais e culturais, coube ao 35, aos dançarinos do 35, como entidade. Assim, no meu tempo, com o meu Conjunto, eles tinham a missão de divulgar e promover diversas danças, e é o que hoje se faz em um CTG, mas naquela época não existiam tantos CTGs. O 35 foi fundado em 1948, a partir daí é que começa a pesquisa, porque ninguém dançava nada.

X.X. - Em que ano mais ou menos se começa a ter grupos de dança nos CTGs?

J.C. - O primeiro grupo dentro do CTG foi formado por mim e pelo Lessa. Fazíamos lá o pezinho, balaio.

X.X. - E quando foi?

J.C. - Isso foi em 1949.

X.X. - Bem no começo.

J.C. - Sim, não existia isso. No ano de 1949 que levamos aos Centros de Tradições e à Comissão Estadual de Folclore, que não conhecia esse sistema até àquela altura e nos incentivou. Em 1954, eu e meu conjunto fomos representando o folclore do Rio Grande do Sul no IV Centenário de São Paulo, que reuniu manifestações artísticas e culturais de todo o Brasil. Nessa ocasião, então, representamos o Estado com canções, com gaúchos montados a cavalo, prendas ${ }^{14}$, e tudo que era do nosso conhecimento nós levamos e apresentamos no Ibirapuera ${ }^{15}$.

X.X. - No início da década de 1960 o público recebia bem esta forma de ter danças folclóricas no palco?

J.C. - Primeiro lugar, temos que diferenciar o panorama atual do antigo. O meu Conjunto e o Conjunto de Folclore Internacional ${ }^{16}$ eram conjuntos profissionais. Vou repetir, profissionais [ênfase]. Nós fizemos da arte uma profissão. O que tu encontras frequentemente agora são manifestações de conjuntos de CTGs e que dançam para divulgar, promover e para participar artisticamente, mas não tinham o caráter profissional. Nós encaramos a arte do folclore como profissão e não somente como manifestação de reprodução. Tínhamos o cuidado de preservar e manter com a maior fidelidade as roupas, a identidade musical

13 Universidade Federal do Rio Grande do Sul.

14 Denominação atribuída na cultura gaúcha às mulheres. Nas danças apresentam-se usando vestido longo e rodado, manga longa tendo os cabelos presos com uma flor ou fita.

15 Parque da cidade de São Paulo.

16 Conjunto de Folclore Internacional Os Gaúchos, grupo de dança fundado em 1959 na cidade de Porto Alegre. 
e coreográfica. O que o Conjunto Internacional se permitia o direito era estilizar e fazer arranjos com toda a arte e toda a beleza que eles sabiam transmitir. Não havia choque, não havia pretensão maior, cada um preservou as suas características e sempre nos aplaudimos profundamente. Os CTGs é que não tinham estrutura cultural para entender, os elementos, às vezes, eram muito simples e não entendiam. O Conjunto Internacional sempre teve pessoas de elevado nível de conhecimentos literários, cultural e artístico o que permitia, então, fazer no palco os arranjos que eles realizaram. Sendo que a Nilva ${ }^{17}$ foi a grande coreógrafa e a grande cabeça das apresentações do Conjunto. Assim como as danças originais, que nunca ninguém tinha visto, as demais eram apresentadas pelos Tropeiros da Tradição com pesquisa original e direta minha.

X.X. - Sobre os CTGs, gostaria de saber se chegaram aos bailes algumas danças oriundas da Argentina e do Uruguai, como o tango, a chacareira? Este tipo de dança chegou ao CTG?

J.C. - Sempre há os que querem novidade, os elementos particulares, para serem originais e se fazerem presentes como capacitação cultural e artística. Então, usamos desses conhecimentos, às vezes não muito sérios nem muito profundos, para fazer apresentações que às vezes desfiguram, não só o folclore do Rio Grande do Sul, como também do Uruguai e da Argentina. Surgiram muitos conjuntos artísticos e eles vinham, olhavam e apresentavam. Como até hoje fazem, por exemplo, usando gaita na chacareira; isso não se dança com gaita, se dança com violão! Mas como a gaita é gaúcha, eles acham que vale tudo. Vale para quem não conhece, para quem não está ciente da responsabilidade que tem, da arte de bem representar seu país, sua gente, sua raça.

X.X. - Sobre a Comissão Estadual de Folclore, o senhor chegou a participar no início?

J.C. - Eu faço parte da Comissão de Folclore do Rio Grande do Sul e participei junto com Barbosa Lessa desde o início. Quando o Conjunto Folclórico Tropeiros da Tradição nasceu, não existia a Comissão ainda. Foi no mesmo ano que nós começamos a divulgar ineditamente as danças é que nasceu, da Comissão Nacional de Folclore, a Comissão Regional Gaúcha, à frente da qual esteve o senhor Dante de Laytano ${ }^{18}$. Eu, no decorrer do tempo, tive o prazer de ser convidado para integrar a Comissão Estadual de Folclore e realizei pesquisas junto com eles, promoções e eventos. Ela teve uma grande importância. A primeira apresentação artística da dança do pezinho e do xote foi da Comissão Estadual de Folclore na $4^{\text {a }}$ Semana de Folclore de Porto Alegre, organizada pela Comissão Estadual. Foram vários eventos: tiro de laço, gineteada, marcação, castração. Em todos eles o meu Conjunto participou. E, à noite, o 35 apresentou o pezinho, o terol e a meia-canha. Foram

17 Nilva Therezinha Dutra Pinto, bailarina, professora e diretora artística do Conjunto de Folclore Internacional Os Gaúchos.

18 Dante de Laytano, nascido em 1908, em Porto Alegre (RS), juiz, consultor jurídico, professor, sociólogo e cronista. Esteve à frente da Comissão Estadual de Folclore do Rio Grande do Sul desde o início. Autor de vários livros, dentre eles Congadas (1945), A Estância Gaúcha (1952), Pequeno Esboço de um Estudo do Linguajar Gaúcho-brasileiro (1961) e O Folclore do Rio Grande do Sul (1987). 
as primeiras três danças que o 35 apresentou. A partir daí é que começou a se difundir. Hoje os CTGs não têm nem conhecimento da diversidade dessas danças. Eu recolhi mais de cem danças, mas eles não estão interessados em conhecer o repertório. Eles querem modificar, para serem originais, para ter a satisfação pessoal do ego. Deturpam os temas originais. Isso é frequente. Eu já editei e publiquei muitos livros, distribuí gratuitamente 350 mil publicações em escolas, bibliotecas públicas, Centros de Tradições. São 25 publicações contendo as pesquisas, coreografias, partituras musicais e eu doava, através de um evento, uma palestra para dar explicações e não apenas deixar os livros.

X.X. - Gostaria que o senhor falasse mais sobre os Tropeiros da Tradição.

J.C. - O primeiro grupo foi Tropeiros da Tradição, em 1953. Eles começaram fazendo dança. Era um grupo que executava as danças que eu pesquisava e que eu dirigia, ou seja, eu montei este Conjunto. Fizemos inúmeros espetáculos, não só em Porto Alegre como também no interior, em São Paulo e no Ceará. Eu fazia apresentações com um grupo de mais ou menos 22 figuras, entre dançarinos e músicos. Esse primeiro conjunto que deu vazão para o nascedouro de todas as outras manifestações e que representou o Rio Grande do Sul no IV Centenário de São Paulo, em 1954, a convite da Comissão Estadual do Folclore, dirigida pelo Professor Dante de Laytano. Depois surgiu o Conjunto de Folclore Internacional, da Nilva. Ela dançou comigo nos Tropeiros. Era um incipiente movimento que estava nascendo, no qual participaram ela, a irmã dela ${ }^{19}$, o Karam ${ }^{20}$ e eu, formávamos dois pares. Fazíamos apresentações frequentemente em núcleos reservados. E daí começa o movimento de formação das danças que hoje estão sendo apresentadas; mas naquele tempo eram originais, a partir das pesquisas realizadas.

X.X. - Sobre o Conjunto de Folclore Internacional Os Gaúchos, o que o senhor lembra sobre sua formação?

J.C. - A Nilva, foi uma das fundadoras do Conjunto e é uma excelente professora e ela é responsável por grande parte do êxito das manifestações folclóricas do Anchieta ${ }^{21}$. Os Gaúchos é o segundo conjunto folclórico do Rio Grande do Sul.

X.X. - Teve alguma época em que os dançarinos do Conjunto da Nilva dançaram no Conjunto Tropeiros da Tradição?

J.C. - Não. A Nilva, a Nilza e o Karam foram fundadores do CFI porque eles não se limitavam somente às danças do Folclore Rio-grandense. A Nilva como estudiosa e capacitada

19 Nilza Dutra Pinto Binotto, bailarina e professora de inglês, participou da primeira formação do Conjunto de Folclore Internacional Os Gaúchos.

20 Jorge Karam. Dançarino do 35 CTG, participou da primeira formação do Conjunto de Folclore Internacional Os Gaúchos.

21 Colégio Anchieta, instituição de ensino básico regular. 
bailarina de primeira, pegou os temas do Uruguai e da Argentina e incluiu no programa deles. Por isso o nome Conjunto de Folclore Internacional Os Gaúchos; era internacional. Os Tropeiros da Tradição atuavam dentro da seleção de temas pesquisados por mim e pelo Lessa do folclore do Rio Grande do Sul, mas não adotamos temas do folclore internacional. Só apresentamos temas inéditos que foram tirados das fitas e gravações, ensaiados e apresentávamos nos palcos de espetáculos daquela época: Teatro São Pedro, na Universidade. Nos grandes eventos, nos apresentávamos só com roupas típicas do Rio Grande do Sul e com temas exclusivamente do Rio Grande do Sul. O Conjunto Internacional já tinha uma diversificação e foi aumentando seu repertório.

X.X. - O Conjunto do senhor chegou a ajudar o Conjunto de Folclore Internacional na parte de danças gaúchas?

J.C. - Acontece o seguinte: nós estávamos incipientes, alguns rapazes que dançavam com a Nilva também acabaram dançando comigo. Então, o intercâmbio entre nós era constante e não havia disputa entre o melhor e o pior. Existia um Conjunto de Folclore Internacional e o Conjunto Tropeiros da Tradição, que eram danças originais do Rio Grande do Sul. Sempre nos demos muito bem, eu tenho uma gratidão muito grande, principalmente a Nilva. Eles completaram recentemente cinquenta anos, eu mandei minha mensagem porque eles desempenharam um papel muito importante, não só atuando no Rio Grande do Sul, na América, Uruguai e Argentina, mas também em outros Estados brasileiros. Eles têm muita qualidade artística e apresentavam formas estilizadas, o que meu conjunto não apresentava, eu me ative à fidelidade dos temas pesquisados. O Conjunto Internacional fazia estampas, como a Nilva já deve ter te explicado, enriquecida com repertório de roupas, instrumentos, cantigas. Então, por isso ele era também muito solicitado e apresentava frequentemente grandes espetáculos educacionais, culturais e artísticos, eventos, promoções, como o meu também. Mas sempre guardamos o maior respeito e admiração recíproca.

X.X. - O senhor gostaria de acrescentar mais alguma coisa?

J.C. - Você é ligada à Educação Física, não é?

X.X.- Sim.

J.C. - Eu dei aula aí na Faculdade ${ }^{22}$ para as alunas, quando a Escola era no antigo campo do Cruzeiro ${ }^{23}$ e ninguém conhecia as danças. Ficou para a Escola uma cartilha, com as danças e explicações. Eu fui muitas vezes lá, gratuitamente, para divulgar entre os educadores e professores os temas que eu tinha pesquisado, para que eles pudessem utilizar. Eu

22 Referência à Escola de Educação Física, Fisioterapia e Dança da Universidade Federal do Rio Grande do Sul.

23 Esporte Clube Cruzeiro. 
não sou professor, eu sou simplesmente um "dançador" das coisas do Rio Grande do Sul. Eu passei apenas o que eu vi, o que eu pesquisava. Porque o sapateio eu não aprendi em escola especial, eu aprendi da escola da vida, dos dançarinos, cantadores, das senhoras. Eu hoje estou ensinando as danças inéditas, que eu pesquisei e aprendi. É isso que eu posso fazer. O que eu tenho obrigação é que seja fiel, e que as pessoas possam reproduzir com fidelidade, porque aqueles que me ensinaram, o fizeram com amor, com carinho, com respeito e com dignidade. E é isso que eu transmito nos meus espetáculos, nas minhas cantorias e nas gravações que fiz inéditas.

X.X. - Agora aqui na Faculdade, tanto no curso de Dança quanto no curso de Educação Física, tem uma disciplina de Danças Tradicionais Gaúchas.

J.C. - Eu sempre achei que a Educação Física que tem didática de ensino, que tem forma de arte e comunicação do exercício, que a dança não significa só ritmo e melodia, significa exercício, inspiração, abdômen, postura, equilíbrio. Essas coisas pertencem à Educação Física, e uma forma de expressão e arte através do folclore que é a vida do povo. Se a Educação Física não aproveita, é uma pena. Lamentavelmente, o Movimento Tradicionalista tem deturpado essas manifestações, feito da arte coreográfica e musical um espetáculo circense. Até desfigurando o figurino. A roupa não dança. Quem dança é o homem, mas a roupa identifica. Se você não está adequadamente vestido, você pode parecer, mas não é e a pessoa precisar ser. Isso é consciência de origem, de identidade, de terra, de herança.

X.X. - Eu gostaria de agradecer a sua disponibilidade para conceder este depoimento. Obrigada!

\section{REFERÊNCIAS}

CÔRTES, João Carlos D’Ávila Paixão; LESSA, Barbosa. Danças e andanças da tradição gaúcha. Porto Alegre: Garatuja, 1975.

. Falando em Tradição \& Folclore Gaúcho: excertos jornalísticos. 1981.

. Origem da semana farroupilha e primórdios do movimento tradicionalista. Porto Alegre: Evangraf, 1994.

. Manual de danças gaúchas. 7. ed. São Paulo: Irmãos Vitale, 1997.

FAGUNDES, Antônio Augusto. Depoimento de Antônio Augusto Fagundes: Projeto Garimpando Memórias. Porto Alegre: Centro de Memória do Esporte - Esef/Ufrgs, 2011.

LAYTANO, Dante de. Folclore do Rio Grande do Sul: levantamento dos costumes e tradições gaúchas. 2. ed. Caxias do Sul: EDUCS, Porto Alegre: Escola Superior de Teologia São Lourenço de Brindes, Nova Dimensão, 1987.

Recebido em: junho/2016

Aprovado em: maio/2017 